See Article page 1685 .

\section{Commentary: Adjuvant therapy in resected T1 2N0 non-small cell lung cancer: Surgeons should lead}

\author{
Neel P. Chudgar, MD, and Brendon M. Stiles, MD
}

Woodard and colleagues ${ }^{1}$ do an outstanding job at summarizing seminal adjuvant trials for patients with resected non-small cell lung cancer (NSCLC). Historically, it has been hard for thoracic surgeons to get excited about adjuvant therapy. Adjuvant chemotherapy in the groundbreaking International Adjuvant Lung Cancer Trial only improved 5-year survival from $40.4 \%$ to $44.5 \%$. $^{2}$ Although subsequent trials suggested greater benefit, the Lung Adjuvant Cisplatin Evaluation Collaborative analysis estimated the absolute survival benefit of adjuvant chemotherapy at only $5.4 \%$ at 5 years for all resected stage IB through III patients. ${ }^{3}$ For patients with stage IB disease, the data are even less inspiring. Kris and colleagues ${ }^{4}$ summarized key clinical trials and graphically showed that surgery alone saves the lives of 6- to 20 -fold more patients with stage IB disease than does the addition of chemotherapy. ${ }^{4}$ The American Society of Clinical Oncology ${ }^{4}$ Practice Guideline Update in 2017 did not recommend routine adjuvant chemotherapy for patients with stage IA and IB disease. Surgeons could therefore be forgiven for being skeptical about the adjuvant space.

But times are changing. The molecular classification of lung cancer has evolved considerably, with drugs approved for at least 8 various molecular subtypes of stage IV NSCLC, where response rates and survival are markedly improved

\footnotetext{
From the Department of Cardiothoracic and Vascular Surgery, Montefiore Medical Center and Albert Einstein College of Medicine, Bronx, NY.

Disclosures: Dr Stiles reports receiving consulting and speaker fees from AstraZeneca, Pfizer, and Gala Therapeutics and advisory board fees from Genentech and Bristol Myers Squibb. He is on the board of the Lung Cancer Research Foundation, and his wife receives stock and salary from Xalud and PPD. The other author reported no conflicts of interest.

The Journal policy requires editors and reviewers to disclose conflicts of interest and to decline handling or reviewing manuscripts for which they may have a conflict of interest. The editors and reviewers of this article have no conflicts of interest.

Received for publication June 30, 2021; revisions received June 30, 2021; accepted for publication July 1, 2021; available ahead of print July 14, 2021

Address for reprints: Brendon M. Stiles, MD, Department of Cardiothoracic and Vascular Surgery, Montefiore Medical Center and Albert Einstein College of Medicine, 111 E 210th St, Bronx, NY 10467 (E-mail: brstiles@montefiore.org).

J Thorac Cardiovasc Surg 2022;163:1693-4

$0022-5223 / \$ 36.00$

Copyright (C) 2021 by The American Association for Thoracic Surgery

https://doi.org/10.1016/j.jtcvs.2021.07.006
}
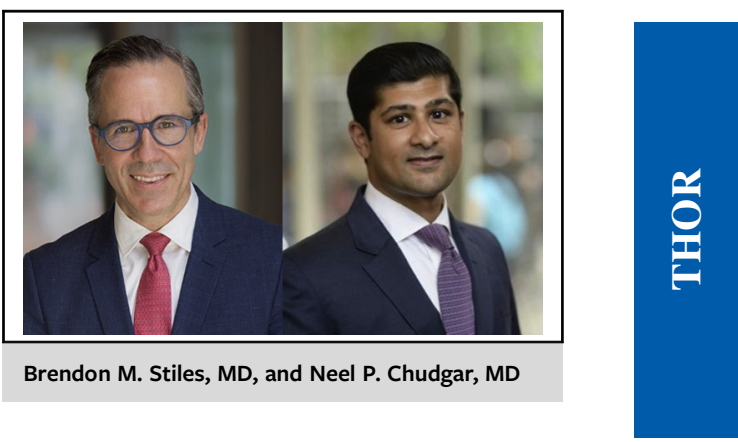

compared with chemotherapy. And many patients who don't harbor 1 of those targetable alterations have shown dramatic responses to anti-PD1/PD-L1 immunotherapy, particularly those patients whose tumors are PD-L1 positive. It is only natural that these personalized drugs make their way into earlier-stage disease. The ADAURA trial is potentially paradigm-changing, showing a dramatic improvement in disease-free survival (DFS) in patients with resected epidermal growth factor receptor-mutated tumors. ${ }^{5}$ Even in patients with stage IB disease (32\% of the trial cohort), there was a significant and provocative improvement in DFS (hazard ratio, $0.39 ; 95 \%$ confidence interval, 0.18-0.76). The adjuvant immunotherapy space is quite active as well. Since the submission by Woodard and colleagues, ${ }^{6}$ results from Impower010 were presented (at the American Society of Clinical Oncology 2021 annual meeting), discussing a trial of adjuvant atezolizumab in patients with resected stage IB to IIIA NSCLC (12\% stage IB). The study met its primary end point of improved DFS in patients with PD-L1 positive stage II or IIIA disease, although the data weren't mature enough to evaluate effects in patients with stage IB disease. Nevertheless, the die has been cast and immunotherapy will likely soon become a part of the adjuvant treatment landscape. In the bigger picture, comprehensive biomarker testing is clearly indicated in the majority of patients with lung cancer.

With changes rapidly coming, it is surgeons who must lead the oncology care of patients with early-stage NSCLC, particularly those without established nodal metastases. We assign disease stage to these patients, decide to whom to give neoadjuvant therapy (another evolving space), know whether or not patients had an adequate lymphadenectomy, 
are typically the first to review the pathology and order molecular tests, and have the best understanding of high risk features. The quality of surgical staging and our ability to safely get patients returned to intended oncologic therapy are critical aspects of multidisciplinary care. The relationship that surgeons develop with their patients allows us to understand their individual treatment goals as well as their ability to tolerate adjuvant therapy. Without doubt, a surgeon's opinion is often the deciding factor for patients weighing the risks versus benefits of adjuvant therapy. We therefore must know the trial data and insist on comprehensive biomarker testing. Hopefully, the recent, remarkable advances and improvements in DFS with targeted therapy will lead to improvements in overall survival and to more patients cured of their lung cancer. We anticipate that they will.

\section{References}

1. Woodard GA, Li A, Boffa DJ. Role of adjuvant therapy in T1-2N0 resected non-small cell lung cancer. J Thorac Cardiovasc Surg. 2022;163:1685-92.

2. Arriagada R, Bergman B, Dunant A, Le Chevalier T, Pignon JP, Vansteenkiste J. Cisplatin-based adjuvant chemotherapy in patients with completely resected nonsmall cell lung cancer. N Engl J Med. 2004;350:351-60.

3. Pignon JP, Tribodet H, Scagliotti GV, Douillard JY, Shepherd FA, Stephens RJ, et al. Lung adjuvant cisplatin evaluation: a pooled analysis by the LACE Collaborative Group. J Clin Oncol. 2008;26:3552-9.

4. Kris MG, Gaspar LE, Chaft JE, Kennedy EB, Azzoli CG, Ellis PM, et al. Adjuvant systemic therapy and adjuvant radiation therapy for stage I to IIIA completely resected non-small cell lung cancer cancers: American Society of Clinical Oncology/Cancer Care Ontario practice guideline update. J Clin Oncol. 2017; 35:2960-74.

5. Wu YL, Tsuboi M, He J, John T, Grohe C, Majem M, et al. Osimertinib in resected EGFR-mutated non-small-cell lung cancer. N Engl J Med. 2020;383:1711-23.

6. Wakelee HA, Altorki N, Zhou C, Csoszi T, Vynnychenko IO, Goloborodko O, et al. Impower010: primary results of a phase III global study of atezolizumab versus best supportive care after adjuvant chemotherapy in resected stage IBIIIA NSCLC. Available at: https://ascopubs.org/doi/abs/10.1200/JCO.2021.39. 15_supp1.8500. Accessed July 16, 2021. 